\title{
OPTHALMOPLEGIC MIGRANE WITH RECURRENT SIXTH NERVE PALSY: A RARE PRESENTATION OF HEADACHE IN A YOUNG LADY
}

\author{
MONZURUL H CHOWDHURY ${ }^{1}$, ZANNATUN NUR ${ }^{1}$, HOSNE ARA BEGUM ${ }^{1}$, MD. SHAHRIAR MAHBUB ${ }^{1}$, \\ HAM NAZMUL AHASAN ${ }^{2}$
}

\begin{abstract}
:
Migraine is a common presentation of headache but migraine with opthalmoplegia with third nerve palsy is rare and with fourth or sixth nerve palsy is very rare. Although it represents a benign course, duration and severity are variable among the patients. We demonstrated a young lady presenting with right hemicranial headache for 12 days with several episodes of vomiting. She also complained of double vision for 7 days. The headache started from the inner canthus of right eye and gradually spread throughout the right half of head over 2 hours and was throbbing in nature. She also complained of double vision from 5th day after onset of headache. Interestingly, she informed similar types of attack for two episodes in last 1 year which persisted for around 22-25 days each time. On examination, she appeared ill looking with convergent squint on right lateral gaze. Cranial nerves examinations showed all the cranial nerves were intact except right sixth cranial nerve palsy. Laboratory investigations and neuroimaging were normal. Our case fulfilled the International Classification of Headache Disorders (ICHD II) criteria for opthalmoplegic migraine with recurrent six nerve palsy which responded dramatically with prednisolone therapy $1 \mathrm{mg} / \mathrm{kg} /$ day which also prevented recurrence within 6 months.
\end{abstract}

Keyword: Migraine, Opthalmoplegic migraine, Abducens nerve palsy.

\section{Introduction:}

Migraine is a common presentation of headache and about $28 \%$ of patients presents with headache fulfilling the criteria of migraine, second only to tension-type headache. ${ }^{1}$ The prevalence of migraine peaks between 25 and 55 years. ${ }^{2}$ Although migraine is common, migraine with opthalmplegia is a rare presentation, with an incidence of approximately 0.7 per million and mostly in young women. ${ }^{3}$ In opthalmoplegic migraine (OM), headache is unilateral with opthalmoplegia in the same side. The headache precedes ophthalmoplegia by several days. 4 Opthalmoplegia is usually caused by third nerve palsy and very rarely with either fourth or sixth nerve palsy. In OM, abducens palsy appears to be 10 -fold less frequent than oculomotor palsy, with an even rarer effect on the trochlear nerve. ${ }^{5}$ Although the disease process represents a benign course in most patients but the duration and severity are variable. It usually lasts for 2-4 weeks without any sequel. Many cases demonstrated a recurrent episode of attack within 1 year. In present case, we showed a young lady presenting with migraine with recurrent sixth nerve palsy on the same side.

\section{Case:}

An 18 years old young unmarried women attended us with complaints of right hemicanial headache for 12 days with several episodes of vomiting. She also complained of double vision for the last 7 days. The headache started from the inner canthus of right eye which gradually spread throughout the right half of her head over 2 hours and was throbbing in nature. The intensity of headache was severe and persisted most of the time of the day. It was associated with mild photophobia and repeated bouts of vomiting. She did not give any history of aura, blurred vision, paresthesia, convulsion, syncope or fever. However, she complained double vision 5 days after the onset of

1. Postgraduate Trainee, Department of Medicine, Dhaka Medical College Hospital, Dhaka

2. Professor and Head, Department of Medicine, Dhaka Medical College, Dhaka

Correspondence: Dr. Monzurul Hasan Chowdhury, Postgraduate trainee, Department of Medicine, Dhaka Medical College Hospital. E-mail: drchowdhury@doctors.org.uk 
headache only on right horizontal gaze. She didn't face any difficulties during reading. She gave no history of alcohol ingestion, intake of cheese, chocolate and oral contraceptives, no demonstrable stress and emotional or head trauma. Interestingly, she informed that she experienced similar types of attack for 2 episodes in last 1 year. Each episode persisted for around 22-25 days. Each episode ended with improvement of diplopia first and than headache with treatment of migraine only.

On examination, she appeared ill looking without any abnormal general examination finding except a convergent squint on right lateral gaze (Fig.-1). Cranial nerves examinations showed all the cranial nerves were intact except right sixth cranial nerve palsy. Motor and sensory examination was normal. All other systemic examinations were normal.

Routine loboratory investigations of CBC, ESR, Hb\% and Urine R/M/E were normal. Inflammatory markers were also normal. CSF study showed all the parameters are within the normal limits. Neuroimaging with CT head, MRI and MRA were also done to exclude any demonstrable pathology and all results were normal.

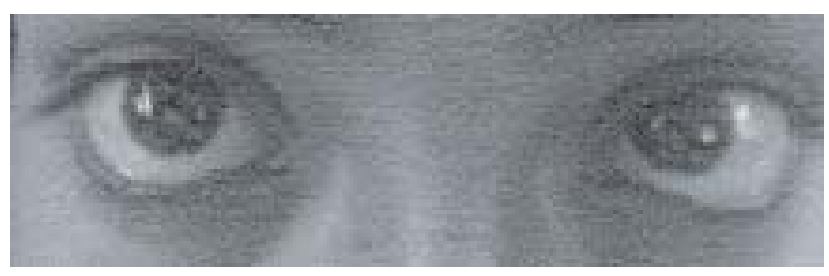

Fig.-1: At presentation, right sided $6^{\text {th }}$ nerve palsy during right lateral gaze without any affect on left lateral gaze.

After confirmation of the idiopathic nature of the disease, we started oral prednisolone $1 \mathrm{mg} / \mathrm{kg} / \mathrm{day}$. Surprisingly, the patient started to improve within 48 hours of starting the treatment. Diplopia started to improve and completely disappeared within 1 week. Headache also started to reduce and completety disappeared after another 1 week. We discharged the patient and advised for follow up within 2 weeks time. Follow up visit was unremarkable and we gradually tapered the dose of steroid (Fig.-2).

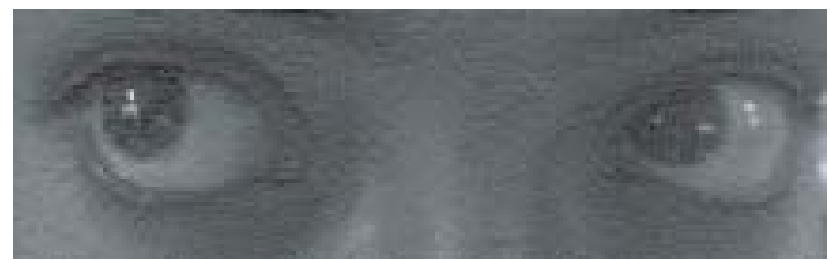

Fig.- 2: Improvement of $6^{\text {th }}$ nerve palsy during right lateral gaze after one week of treatment

\section{Discussion:}

Opthalmoplegic migraine was described under the heading of 'Cranial neuralgias and central causes of facial pain' and was defined as consisting of at least two episodes of headache accompanied or followed within 4 days of its onset by paresis of one or more cranial nerves- third, fourth and/or sixth after excluding parasellar, orbital fissure and posterior fossa lesions with appropriate investigations. ${ }^{6}$ Although the disease is considered as idiopathic in nature with a benign self-limiting course, different authors proposed different pathological processes. Some showed inflammatory demyelinating process involving the third nerve root since the course is self limiting and recurrent. The MRI during active disease showed third nerve root enhancement with gadolinium. ${ }^{7}$ Another study also showed gadolinium enhancement of intrapontine region near the abducens nerve nucleus during sixth nerve palsy. ${ }^{8}$ Others proposed ischemic change or compressive neuropathis. ${ }^{9}$ Our patients fulfilled the set criteria of OM after exclusion of secondary causes by laboratory investigations and neuroimaging techniques. The normal findings also excluded the Tolosa Hunt's syndrome and other structural lesions in pons and cavernous sinus.

The definitive treatment of OM has not yet been established. The role of prednisolone in active desease is still controversial. While one study showed good response with steroid, others demonstrated no improvement rather than a self limiting course. ${ }^{10,11}$ Besides, all these studies, one showed steroid not only improved the acute attack but also prevented the recurrence within one year period. ${ }^{12}$ Our present case also responded well with the use of steroid and also showed no recurrence within 6 months.

In conclusion, our case fulfilled the ICHD II criteria for opthalmoplegic migrane with recurrent six nerve palsy which responded dramatically with prednisolone therapy $1 \mathrm{mg} / \mathrm{kg} /$ day and also prevented recurrence within 6 months. 


\section{References:}

1. Gobel, H, Petersen-Braun M, Soyka D. The epidemiology of headache in Germany: a nationwide survey of a representative sample on the basis of the headache classification of the International Headache Society. Cephalalgia 1994; 14: 97-106.

2. Lipton, RB, Stewart WF, von Korff M. Burden of migraine: societal costs and therapeutic opportunities. Neurology 1997; 48: S4-9.

3. Hansen, SL, Borelli-Moller L, Strange P, et al. Ophthalmoplegic migraine: diagnostic criteria, incidence of hospitalization and possible etiology. Acta neurologica Scandinavica 1990; 81: 54-60.

4. Çelebisoy N, Sirin H, Gökçay F. Ophthalmoplegic migraine: Two patients, one at middle age with abducens palsy. Cephalalgia 2004;25:151-153.

5. Crevits L, Verschelde H, Casselman J. Ophthalmoplegic migraine: An unresolved problem. Cephalalgia 2006;26: 1255-1259.

6. Headache Classification Subcommittee of the International Headache Society. The International Classification of Headache Disorders. Cephalalgia 2004; 24(Suppl 1):131-2.
7. Carlow TJ. Oculomotor ophthalmoplegic migraine: Is it really migraine? J Neuroophthalmol 2002;22:215-221.

8. Lee TG, Choi WS, Chung KC. Ophthalmoplegic migraine with reversible enhancement of intraparenchymal abducens nerve on MRI. Headache 2002; 42: 140-141.

9. Manzouri B, Sainani A, Plant GT, et al. The aetiology and management of long-lasting sixth nerve palsy in ophthalmoplegic migraine. Cephalalgia 2007; 27: 275-278.

10. Crevits L, Verschelde H, Casselman J. Ophthalmoplegic migraine: An unresolved problem. Cephalalgia 2006; 26: 1255-1259.

11. Smith CD, Reeves AG. Amelioration of ophthalmoplegic migraine by prednisone: A case report. Headache 1986; 26:93-94.

12. Vasconcelos LP,. Stancioli FG, Leal JC, et al. Ophthalmoplegic Migraine: A Case with Recurrent Palsy of the Abducens Nerve. Headache [online] 2008. Availbale at: http://www3.interscience. wiley.com/cgi-bin/fulltext/120173726/HTMLSTART Aceessed May 52009. 